\title{
HUBUNGAN LINGKAR LENGAN ATAS (LILA) IBU HAMIL TRIMESTER III DENGAN BERAT BAYI LAHIR TAHUN 2019
}

\author{
Kristina Paskana ${ }^{1}$ \\ ${ }^{1)}$ Akademi Kebidanan Manna Bengkulu Selatan \\ kristinapaskana04@gmail.com
}

\begin{abstract}
ABSTRAK
Badan Kesehatan Dunia (WHO) menyatakan bahwa angka kejadian Berat Badan Lahir Rendah (BBLR) merupakan indikator masalah kesehatan publik, diantaranya kesehatan ibu, malnutrisi, dan buruknya fasilitas kesehatan (Riskesdas, 2018). Upaya memaksimalkan kebutuhan nutrisi saat hamil berguna untuk menekan kejadian BBLR (Kemenkes RI, 2019). Tujuan penelitian ini untuk mengetahui hubungan lingkar lengan atas ibu hamil trimester III dengan berat bayi lahir di Puskesmas Seginim. Metodologi penelitian menggunakan survei analitik dengan pendekatan cross sectional. Populasi yaitu seluruh ibu post partum periode April-Juni 2019 berjumlah 51 orang. Data dianalisis menggunakan chi-square. Hasil Penelitian : ibu dengan LILA $<23,5$ sebagian besar melahirkan bayi berat lahir $<2.500$ gr sebesar $11,8 \%$, dan ibu dengan LILA $>23,5$ sebagian besar melahirkan bayi dengan berat $>2.500$ gr sebesar $74,5 \%$. Uji statistik chisquare menunjukkan 15,3 dan nilai $\rho=0,000<\alpha=0,05$. Maknanya: Ada hubungan LILA ibu hamil trimester III dengan berat bayi lahir di Puskesmas Seginim Tahun 2019.
\end{abstract}

Kata kunci : berat bayi lahir, kurang energi kronik, lingkar lengan atas

\begin{abstract}
The World Health Agency (WHO) states that, the incidence rate of BBLR in population level is an indicator of public health problems, including maternal health, malnutrition, and poor health facilities (Riskesdas, 2018). Maximizing nutritional needs during pregnancy is done to minimize the incidence of BBLR (Kemenkes RI, 2019). The purpose of the study knows the relationship of upper arm circumference III trimester pregnant women with baby birth in Seginim Public Health Center. The research methodology uses an analytical survey with a cross sectional approach. The population is entire postpartum mother of April to June 2019, amounting to 51 people. Data analyzed using Chi-square. Research result: Mother with LILA $<23.5$ mostly gave birth weight baby birth $<2,500 \mathrm{gr}$ by $11.8 \%$, and mother with LILA $>23.5$ mostly give birth to a baby with weight $>2,500 \mathrm{gr}$ of $74.5 \%$. The Chi-square statistical test shows 15.3 and the value $\rho=$ $0.000<\dot{\alpha}=0.05$. Meaning: There is a link between the upper arm circumference of the III trimester of pregnant women with the weight of babies born in Seginim Public Health Center in 2019 years.
\end{abstract}

Keyword: baby birth weight, less chronic energy, upper arm circumference 


\section{PENDAHULUAN}

Pemenuhan gizi seimbang pada ibu hamil sangat penting karena status gizi ibu akan sangat berpengaruh terhadap kondisi bayi dalam kandungan. Status gizi ibu yang tidak baik dapat berisiko ibu mengalami Kekurangan Energi Kronik (KEK), yang dapat melahirkan bayi BBLR (Murtiyarini, 2012).

Sementara itu, data yang dipaparkannya terbaca angka kematian neonatal (AKN) 15 per $1000 \mathrm{KH}$ menurut SDKI tahun 2017. Kematian neonatal di desa/kelurahan 0-1 per tahun sebanyak 83.447, di Puskesmas kematian neonatal 7-8 per tahun sebanyak 9.825, dan angka kematian neonatal di rumah sakit 18 per tahun sebanyak 2.868 dan salah satu pencetus kematian tersebut karena kasus BBLR yaitu 19\% (Kemenkes RI, 2019). Pada masa kehamilan seorang wanita harus memenuhi kebutuhan fisiknya terhadap nutrisi yang disarankan minimal 11-12 kg selama masa kehamilan. Hal itu dilakukan untuk mencegah kelahiran bayi dengan BBLR (Widjaya, 2010).

Menurut WHO angka kejadian BBLR lebih dari 15,5\% dari bayi yang lahir per tahunnya sehingga Indonesia mendapat peringkat 9 tertinggi di dunia. Pada masa kehamilan jika kebutuhan gizi tidak tercukupi sering mengakibatkan KEK dan Anemia gizi pada ibu hamil. Saat ini LILA ibu hamil yang kurang dari $23,5 \mathrm{~cm}$ masih menjadi indikator yang digunakan untuk menentukan masalahmasalah gizi pada ibu. Padahal masalah gizi pada ibu hamil dapat berdampak pada kelahiran BBLR. Risiko memiliki bayi BBLR semakin meningkat akibat masalah gizi atau KEK yang terjadi pada Wanita Usia Subur (WUS). Tercatat ada 35,65\% KEK terjadi pada WUS. Masalah tersebut dapat menghambat pertumbuhan janin pada saat kehamilan (Ekawaty, 2015).

Data Dinas Kesehatan Propinsi Bengkulu kasus BBLR tahun 2018 sebanyak 6,25\% (Dinkes Provinsi Bengkulu, 2018), sedangkan di Bengkulu Selatan jumlah kasus BBLR pada tahun 2018 sebanyak 32 orang $(0,85 \%)$ ibu hamil yang mengalami KEK sebanyak 9 orang $(0,23 \%)$ (Dinkes Kabupaten Bengkulu Selatan, 2018). Berdasarkan hasil rekapitulasi per tahun di wilayah kerja Puskesmas Seginim tahun 2018 ditemukan ibu melahirkan dengan BBLR berjumlah 8 orang $(1,96 \%)$ dan ibu yang mengalami KEK berjumlah 1 orang $(0,23 \%)$. Berdasarkan hasil pengukuran yang dilakukan terhadap ibu hamil di Puskesmas Seginim tahun 2018 ada 6 orang ibu hamil TM III (20\%) dengan LILA $<23,5 \mathrm{~cm}$ dan 24 orang ibu hamil TM III (80\%) dengan LILA $\geq 23,5 \mathrm{~cm}$.

Berdasarkan latar belakang di atas masih ditemukan adanya kasus BBLR di Puskesmas Seginim maka peneliti tertarik untuk mengetahui hubungan LILA ibu hamil dengan berat bayi lahir dengan judul penelitian "Hubungan Lingkar Lengan Atas Ibu Hamil Trimester III dengan Berat Bayi Lahir di Puskesmas Seginim tahun 2019”.

\section{METODOLOGI}

Penelitian ini dilakukan pada wilayah kerja Puskesmas Seginim pada bulan Juli 2019. Metode penelitian menggunakan metode analitik. Pendekatan yang digunakan dengan metode cross sectional. Pada penelitian ini populasinya adalah seluruh ibu nifas periode April-Juni 2019 yang tercatat di Puskesmas Seginim yaitu sejumlah 51 orang dan diambil dengan teknik total sampling. Pada penelitian ini digunakan data sekunder dari rekam medik di Puskesmas Seginim yaitu data persalinan dan kohort ibu hamil. Analisis data dilakukan secara univariat dan bivariat.

\section{HASIL}

1. Analisis Univariat

a. Lingkar Lengan Atas (LILA) Ibu Hamil TM III di Puskesmas Seginim 
Tabel 1. Distribusi Frekuensi LILA Ibu

Hamil TM III di Puskesmas Seginim

Tahun 2019

\begin{tabular}{ccc}
\hline LLA & f & \% \\
\hline$<23,5$ & 9 & 17,6 \\
$>23,5$ & 42 & 82,4 \\
\hline Jumlah & $\mathbf{5 1}$ & $\mathbf{1 0 0 , 0}$ \\
\hline
\end{tabular}

Berdasarkan tabel dapat dilihat bahwa sebagian besar LILA ibu hamil $(82,4 \%)$ di Puskesmas Seginim $\geq 23,5 \mathrm{~cm}$.

b. Berat Bayi Lahir di Puskesmas Seginim
Tabel 2. Distribusi Frekuensi Berat Bayi

Lahir di Puskesmas Seginim Tahun 2019

\begin{tabular}{ccc}
\hline Berat Bayi Lahir & f & $\mathbf{\%}$ \\
\hline$<2.500 \mathrm{gr}$ & 10 & 19,6 \\
$>2.500 \mathrm{gr}$ & 41 & 80,4 \\
\hline Jumlah & $\mathbf{5 1}$ & $\mathbf{1 0 0}$ \\
\hline
\end{tabular}

Berdasarkan dari tabel dapat dilihat bahwa sebagian besar berat bayi lahir di Puskesmas Seginim tahun $2019>2.500$ gr yaitu 41 orang $(80,4 \%)$.

2. Analisis Bivariat

Analisis bivariat dilakukan dengan menggunakan uji statistik yaitu uji $\mathrm{X}^{2}$ (chisquare).

Tabel 3. Hubungan LILA Ibu Hamil Dengan Berat Bayi Lahir di Puskesmas Seginim Tahun 2019

\begin{tabular}{|c|c|c|c|c|c|c|c|c|}
\hline \multirow{2}{*}{ LLA } & \multicolumn{4}{|c|}{ Berat Bayi Lahir } & \multicolumn{2}{|c|}{ Total } & \multirow{2}{*}{$\mathbf{X}^{2}$} & \multirow{2}{*}{$\rho$} \\
\hline & $<2.500$ & $\%$ & $>2.500$ & $\%$ & $\mathbf{N}$ & $\%$ & & \\
\hline$<23,5$ & 6 & 11,8 & 3 & 5,9 & 9 & 17,6 & \multirow{3}{*}{15,3} & \multirow{3}{*}{0,000} \\
\hline$>23,5$ & 4 & 7,8 & 38 & 74,5 & 42 & 82,4 & & \\
\hline Jumlah & 10 & 19,6 & 41 & 80,4 & 51 & 100 & & \\
\hline
\end{tabular}

Sumber: Data dari kohort ibu hamil Puskesmas Seginim 2019

Dari tabulasi silang antara LLA dengan Berat Lahir Bayi dapat dilihat bahwa dari 9 ibu hamil trimester III dengan LLA $<23,5$ sebagian besar melahirkan bayi berat lahir $<2.500 \mathrm{gr}$ yaitu sebesar 11,8\%, dan dari 42 ibu hamil trimester III dengan LLA > 23,5 sebagian besar melahirkan bayi dengan berat $>2.500$ gr yaitu sebesar 74,5\%. Berdasarkan hasil uji statistik chi square menunjukkan bahwa nilai $\mathrm{X}^{2}$ hitung = $15,3>X^{2}$ tabel $=3,841$ dan nilai $\rho$ value $=0,000$ $<\alpha=0,05$, berarti signifikan maka ada hubungan antara lingkar lengan atas ibu hamil trimester III dengan berat bayi lahir di Puskesmas Seginim Tahun 2019.

\section{PEMBAHASAN}

Berdasarkan penelitian di Puskesmas Seginim diketahui bahwa terdapat hubungan LILA ibu hamil TM III dengan berat bayi lahir dengan hasil $\mathrm{X}^{2}=15,3>\mathrm{X}^{2}$ tabel $=3,841$ dan nilai $\rho=0,000<\alpha=0,05$. Hasil penelitian ini sependapat dengan penelitian yang dilakukan Sumiaty (2016), dengan hasil bahwa masalah KEK sangat berhubungan dengan kejadian BBLR sehingga memiliki risiko 4 kali menyebabkan kelahiran BBLR (Restu \& Kemenkes Palu, 2016).

Menurut Riskesdas (2018) bahwa pentingnya memastikan ibu hamil sudah memilih makanan bergizi tinggi dan rutin lakukan pengecekan penambahan berat badan saat hamil, dan itu sudah sesuai ketentuan usia kehamilan, sebab kalau tidak mencapai target, ibu hamil berisiko melahirkan bayi dengan BBLR (Riskesdas Jakarta, 2018).

Menurut Widjaya (2010) Pada masa kehamilan seorang wanita harus memenuhi kebutuhan fisiknya terhadap nutrisi yang disarankan minimal 11-12 kg selama masa kehamilan. Hal itu dilakukan untuk mencegah 
kelahiran bayi dengan BBLR (Widjaya, 2010).

Menurut Sri Widati (2017) ibu yang memiliki status gizi baik bayi yang dilahirkannya akan memiliki berat badan normal tidak BBLR. Status gizi yang tidak baik saat sebelum dan saat hamil yang bias beresiko melahirkan bayi BBLR. (Widati et al., 2017).

Pada observasi yang dilakukan oleh Pudjiadi (2013) menunjukkan wanita yang kekurangan asupan gizi dimasa hamil mengakibatkan kondisi fisik bayi yang dilahirkan tidak sempurna. Kejadian kematian bayi baru lahir akibat premature dan cacat bawaan disebabkan gizi ibu disaat hamil tidak terpenuhi (Solihin, 2013). Upaya yang dapat dilakukan untuk mencegah terjadinya bayi berat lahir rendah (BBLR) dimulai dari melakukan pemeriksaan kehamilan yang rutin dan langsung berkonsultasi jika ada kelainan. Hal tersebut dilakukan dengan, strategi intervensi yang diterapkannya melalui peningkatan akses pelayanan kesehatan semesta, peningkatan kualitas pelayanan pemberdayaan masyarakat dan penguatan tata kelola, yang diikuti oleh peningkatan kualitas pelayanan melalui AMP, dan juga sistem informasi yang tersedia saat ini, seperti STBM smart, digitalisasi KIA dan e-PPGBM (Kemenkes RI, 2019).

Menurut Ekawaty bayi yang lahir dengan kasus BBLR dapat dilahirkan dari ibu dengan riwayat bersalin Premature dan Abortus serta dengan usia $<20$ tahun atau $>35$ tahun (Ekawaty, 2015).

\section{SIMPULAN DAN SARAN}

A. SIMPULAN

1. Sebagian besar $(82,4 \%)$ ibu hamil memiliki LILA $\geq 23,5$.

2. Sebagian besar $(80,4 \%)$ bayi lahir dengan berat $>2.500 \mathrm{gr}$.

3. Terdapat hubungan LILA ibu hamil dengan berat bayi sewaktu lahir di Puskesmas Seginim tahun 2019.

\section{B. SARAN}

1. Bagi Puskesmas

Saran bagi puskesmas agar dapat meningkatkan program di Puskesmas dan kinerja para petugas kesehatan sehingga dapat mengurangi angka prevalensi gizi kurang, KEK, agar tidak terjadi BBLR.

2. Bagi Peneliti

Saran bagi peneliti agar dapat mempertahankan dan meningkatkan mutu dengan pemberian informasi atau konseling terutama tentang gizi ibu hamil.

3. Bagi Peneliti Lain

Saran bagi peneliti lain dapat melakukan penelitian ini dengan faktor-faktor yang lain seperti pendidikan atau status ekonomi.

\section{DAFTAR PUSTAKA}

Dinkes Kabupaten Bengkulu Selatan. (2018). Profil Kesehatan Kabupaten Bengkulu Selatan.

Dinkes Provinsi Bengkulu. (2018). Profil Kesehatan Provinsi Bengkulu.

Ekawaty, D. (2015). Jumlah Bayi Berat Lahir Rendah Masih Tinggi. In FK UGM.

Kemenkes RI. (2019). Strategi Penurunan AKI dan Neonatal. In Rakernas Jakarta.

Murtiyarini. (2012). Nutrisi Murah Dan Sehat Untuk Ibu Hamil. In sarihusada.co.id.

Restu, S., \& Kemenkes Palu, P. (2016). Kurang Energi Kronis (Kek) Ibu Hamil Dengan Bayi Berat Lahir Rendah (Bblr). Jurnal Husada Mahakam, IV(3), 162-170.

Riskesdas Jakarta. (2018). Prevalensi BBLR Di Indonesia. In Riset Kesehatan Dasar.

Solihin, P. (2013). Ilmu Gizi Klinis Pada Anak.

Widati, S., Gunawan, A. M. I., \& Waryana. (2017). Risiko KEK Ibu Hamil Terhadap Kejadian Berat Badan Lahir Rendah di Wilayah Puskesmas Kokap I Kabupaten Kulon Progo. Public Health Hygine Preventive Medicine. 
Widjaya.(2010). Gizi Tepat Untuk Perkembangan

Otak dan Kesehatan Balita. 
